\title{
BMJ Global Health Impact of short-term reconstructive surgical missions: a systematic review
}

\author{
Thom C.C. Hendriks, ${ }^{1,2}$ Matthijs Botman, ${ }^{1,2}$ Charissa N.S. Rahmee, ${ }^{1,2}$ \\ Johannes C.F. Ket, ${ }^{3}$ Margriet G. Mullender, ${ }^{1}$ Barend Gerretsen, ${ }^{4}$ \\ Emanuel Q. Nuwass, ${ }^{5}$ Klaas W. Marck, ${ }^{6}$ Henri A.H. Winters ${ }^{1,2}$
}

To cite: Hendriks TC.C, Botman M, Rahmee CN.S, et al. Impact of short-term reconstructive surgical missions: a systematic review. BMJ Glob Health 2019;4:e001176. doi:10.1136/ bmjgh-2018-001176

Handling editor Soumyadeep Bhaumik

Received 18 September 2018 Revised 19 January 2019 Accepted 25 January 2019

Check for updates

(C) Author(s) (or their employer(s)) 2019. Re-use permitted under CC BY-NC. No commercial re-use. See rights and permissions. Published by BMJ.

${ }^{1}$ Plastic, Reconstructive and Hand Surgery, VU Medisch Centrum, Amsterdam, The Netherlands

${ }^{2}$ Global Surgery Amsterdam, Amsterdam, The Netherlands ${ }^{3}$ Medical library, Vrije Universiteit, Amsterdam, The Netherlands

${ }^{4}$ Koninklijk Instituut voor de

Tropen, Amsterdam, The

Netherlands

${ }^{5}$ Department of Surgery, Haydom Lutheran Hospital, Haydom, Tanzania

${ }^{6}$ Department of Plastic Surgery, Medisch Centrum Leeuwarden, Leeuwarden, The Netherlands

Correspondence to Drs. Thom C.C. Hendriks; thom.hendriks@gmail.com

\section{ABSTRACT}

Introduction Short-term missions providing patients in low-income countries with reconstructive surgery are often criticised because evidence of their value is lacking. This study aims to assess the effectiveness of shortterm reconstructive surgical missions in low-income and middle-income countries.

Methods A systematic review was conducted according to PRISMA guidelines. We searched five medical databases from inception up to 2 July 2018. Original studies of shortterm reconstructive surgical missions were included, which reported data on patient safety measurements, health gains of individual patients and sustainability. Data were combined to generate overall outcomes, including overall complication rates.

Results 0 f 1662 identified studies, 41 met full inclusion criteria, which included 48546 patients. The overall study quality according to Oxford CEBM and GRADE was low.

Ten studies reported a minimum of 6 months' follow-up, showing a follow-up rate of $56.0 \%$ and a complication rate of $22.3 \%$. Twelve studies that did not report on duration or follow-up rate reported a complication rate of $1.2 \%$. Fifteen out of 20 studies (75\%) that reported on follow-up also reported on sustainable characteristics.

Conclusions Evidence on the patient outcomes of reconstructive surgical missions is scarce and of limited quality. Higher complication rates were reported in studies which explicitly mentioned the duration and rate of follow-up. Studies with a low follow-up quality might be under-reporting complication rates and overestimating the positive impact of missions. This review indicates that missions should develop towards sustainable partnerships. These partnerships should provide quality aftercare, perform outcome research and build the surgical capacity of local healthcare systems.

PROSPERO registration number CRD42018099285.

\section{INTRODUCTION}

Conditions that are treatable by reconstructive surgery make up a large part of the global burden of surgical disease. Examples are burns ( 8.1 million disability-adjusted life years $[\mathrm{DALY}]),{ }^{1}$ orofacial clefts $(0.23$ million DALYs $),{ }^{1}$ complex wounds including trauma-related wounds (unknown DALYs, but estimated to be significant), pressure sores

\section{Key questions}

What is already known?

- There is rising concern about the accountability, patient safety and sustainability of short-term reconstructive surgical missions; however, data on these parameters are lacking.

What are the new findings?

- Evidence provided by research on surgical outcomes is limited and of low quality, and the safety of missions is likely to be overestimated by studies in which the quality of follow-up is not reported. Our data suggest that engagement in sustainable development of the local healthcare system and the feasibility of conducting high-quality, long-term follow-up go hand in hand.

What do the new findings imply?

- We call for implementing longer-term outcome research of future missions.

- One approach that could provide a framework to conduct such research, is to implement diagonal development missions. These missions combine the positive impact of the short-term vertical inputs (e.g. providing surgical services) and long-term horizontal investments (e.g. development of sustainable healthcare systems), with the aim of improving access to, and capacity of, the local surgical healthcare systems in the long-term.

$(0.67 \text { million DALYs })^{1}$ or noma (a neglected tropical disease, a roughly estimated 1-10 million DALYs). ${ }^{2}$ Short-term reconstructive surgical missions are a well-established routine method of addressing these conditions and reducing their impact on global health by providing specialised care in underserved populations. ${ }^{3}$ Such missions are commonly short term, disease specific, focus on service delivery and have a tendency to work outside the local healthcare system. This is also referred as a 'vertical approach to healthcare development'.

Despite being a common model, the impact of reconstructive surgical missions is hardly known. ${ }^{56}$ Medical missions in general are 
commonly debated in the literature. ${ }^{7-15}$ There is rising concern about the limited accountability of missions, with little data reported back to healthcare authorities due to a lack of outcome measurements. ${ }^{8}$ Quality of care is debated, as missions often have limited capacity to provide ancillary services or follow-up. ${ }^{16}$ Furthermore, sustainability is questioned in terms of lasting positive impact on the local healthcare system or its cost-effectiveness. The question is whether short-term surgical missions are the most rational allocation of resources to address local healthcare needs. ${ }^{4} 781215$ Ultimately, the ethical implications of surgical volunteerism often ignite debate. ${ }^{1718}$

These concerns are discussed in several reviews of medical missions in low-income and middle-income countries (LMICs). $.^{7} 91012-1519$ For instance, Martiniuk et $a l$ and Roche et al argued that global standards are needed for short-term medical missions, ${ }^{74}$ and Sykes shows that only $6 \%$ of all published studies on medical missions report on empirical data. ${ }^{10}$ Only a few studies reviewed surgical missions specifically. ${ }^{912-15} 19$ Shrime et al systematically compare three types of charitable platforms for global surgery (short-term missions, self-contained surgical platforms and specialty surgical hospitals run by non-governmental organisations [NGOs]). Although they conclude that evidence in the literature is scarce, they state that self-contained temporary platforms and specialised surgical centres appear to provide more effective and cost-effective care than short-term surgical missions, except when no other delivery platform exists. ${ }^{12}$

These reviews provide valuable insights into medical missions in general. However, the diversity of medical and surgical missions is large, which hampers the interpretation of empirical data. This review aims to systematically review evidence on the impact of short-term reconstructive surgical missions specifically, and critically analyses the quality of the available empirical data. In this review, four key aspects are addressed: basic characteristics of missions, patient safety, health gains of individuals and sustainability.

\section{METHODS}

We conducted a systematic review of the literature following the Preferred Reporting Items for Systematic Reviews and Meta-Analysis guidelines. ${ }^{20}$

\section{Inclusion criteria}

All original studies that analysed empirical data of shortterm missions pertaining to reconstructive surgical care in LMICs were eligible. Studies lacking analyses of empirical data, reviews, studies of specialty surgical hospitals that provide continuous year-round care, mobile surgical platforms sent from in-country hospitals, studies in conflicts zones, studies not related to LMICs or studies of patients that were transported to high-income countries (HICs) were excluded. The studies were restricted to English and
Dutch language. No restrictions were applied regarding publication dates. Duplicates were excluded.

\section{Search strategy and data sources}

PubMed, Embase.com, Clarivate Analytics/Web of Science and Open Grey were searched up to 1 July 2018; Proquest up to 1 July 2017 (by CR, TH and JK). The last database was no longer available to us after 2017. The following terms-including synonyms-were used as index terms or free-text words: 'plastic surgery', 'reconstructive surgical procedures', 'cleft lip', 'postburn contractures' or 'noma' combined with 'medical missions', 'humanitarian' or 'charity'. More studies were identified by reviewing the bibliographies of retrieved studies. The full search strategies for all databases can be found in the online supplementary file 1 .

\section{Study selection}

Studies were screened for eligibility by two independent investigators ( $\mathrm{TH}$ and $\mathrm{CR}$ ): in case of disparity, a third author was involved (MB). Two investigators independently extracted the data to create tables and figures (TH and CR).

Data on mission characteristics and individual patientlevel data were extracted and analysed across four key features:

1. Basic characteristics of the missions, including mission length, number of patients who received surgery, and age and gender distribution.

2. Patient safety by means of complication registration. Data were collected on three indicators: follow-up length, follow-up rate and complication rate. The follow-up rate was calculated by the number of patients who completed follow-up divided by the total number of patients who were included for follow-up. The complication rate was calculated as follows: the number of patients with complications divided by the total number of patients who completed follow-up.

3. Health gains: data on surgical outcomes were collected, for example, improvement of range of motion, patient-reported outcome measures (PROMs) or DALYs averted per patient. All reported PROMs were recorded, for example on surgical outcomes, complications or the quality of care provided. All types of formats, questionnaires or any other tool describing these outcomes were included.

DALYs are used to define the overall disease burden over a population and are calculated by 'adding the number of years of life lost due to premature mortality to the number of years of healthy life lost related to disability'. ${ }^{21}$ This means that 1 DALY can be defined as one lost year of healthy life. ${ }^{21}$ Many limitations of this approach are described in the literature. The biggest challenge is that it is not based on health data from countries, but on complex estimation techniques. DALYs are therefore estimations and many concerns exist about their reliability and uncertainty. ${ }^{22}{ }^{23}$ Despite 
these challenges, DALY metrics are commonly applied in global surgery studies. ${ }^{12124}$

4. Sustainable characteristics of missions: studies were reviewed for data on long-term partnerships, training objectives and involvement of local staff. Also, data on the cost-effectiveness of missions were collected. Missions were categorised either as stand-alone or consecutive missions to the same hospital, region or country.

\section{Data analysis and synthesis}

After a pilot, data were extracted independently and in duplicate using a data extraction sheet (TH and CR). Authors were contacted when data on complication registration were missing. Quantitative data synthesis consisted of compiling total number of patients (eg, total number of patients who were included, total number of patients with complications) to generate overall outcomes. Table 1 and the online supplementary appendix file 1 provide details of the data extracted from each reference. Due to the heterogeneity of studies in types of surgery, local healthcare settings or available resources, statistical analyses were not feasible. Study quality assessment was performed independently by authors TH and CR according to the Oxford CEBM Level of Evidence classification ${ }^{25}$ and the GRADE (Grades of Recommendation, Assessment, Development and Evaluation) system. ${ }^{26}$

\section{RESULTS}

The search identified 1662 unique citations. After screening titles and abstracts 1570 studies were excluded because they did not concern short-term reconstructive surgical missions. Ninety-two studies concerned reconstructive surgical missions and were reviewed full-text. Of the full-text studies, 51 were excluded. Please see figure 1 for the screening and selection process. Studies reviewing specialty hospitals missions were excluded, as this was outside the scope of this review. After full-text analyses, 41 met full inclusion criteria (figure 1 and table 1). ${ }^{27-67}$

The studies included predominantly consisted of case series, with 37 studies graded at Oxford CEBM Level IV. The remaining four economic analyses were graded at level IIB. This resulted in a $\mathrm{C}$ grade of recommendations for our review, according to CEBM. The overall GRADE score was 2.7 (low to moderate quality), meaning that our confidence in the effect estimate is limited (table 2). ${ }^{26} 68$

Twenty-eight of 41 studies included pertained to cleft care $(78 \%$ of the total study population). The number of patients in all studies totalled 48546 , with a mean age of 13.4 years (SD 8.5) (table 3). The average mission length was 10 days (SD 3.8; range, 6-21 days). Organisations were active in Africa, South-East Asia, Eastern Europe, and South and Central America. A typical mission team consisted of two or three plastic and/ or maxillofacial surgeons, one or two anaesthetists, a mission coordinator, theatre nurse and one or two resident doctors, totalling 8 to 10 individuals for one single mission. ${ }^{32} 3337464750515458$ Some teams were considerably larger, up to 40 individuals. ${ }^{36}$

Regarding patient safety, nine studies $(22 \%)$ did not report on complications. Twelve studies (29\%) only reported a complication rate without reporting on follow-up length or rate. The overall complication rate in these 12 studies was $1.2 \%$. Ten studies (24\%) reported a follow-up length shorter than 180 days, with a mean follow-up rate of $81.3 \%$ and a complication rate of $7.1 \%$. Ten studies (24\%) provided a follow-up length longer than 180 days, reporting a mean follow-up rate of $56.0 \%$ and a $22.3 \%$ complication rate (table 3 ). Mortality after cleft surgery was reported in three studies, totalling 3 out of 14551 patients included in these studies. ${ }^{16} 2864$ For general reconstructive surgical missions-not specified for a single disease-one single study reported one death $^{54}$ and no mortality was reported in contracture and noma missions.

Twelve studies (29\%) reported on health gains of the mission, reporting heterogeneous methods and outcomes (table 1). Methods used in cleft studies included photographic assessment of aesthetic outcomes, ${ }^{3069}$ speech evaluation $^{1647}$ or DALYs averted. ${ }^{41} 434855$ Three cleft studies evaluated speech functionality postoperatively, either by questionnaires ${ }^{61}$ or speech tests. ${ }^{16} 47$ Study methods were clear and showed overall improvements of speech. Four cleft studies reported on DALYs averted by cleft lip and palate repair surgery. DALYs averted per patient were $3.9,{ }^{43} 6.0^{41}$ and 10.1 per patient. ${ }^{48}$ In three noma missions, a surgeon-reported outcome scale was used to score aesthetic and functional outcome. ${ }^{32} 5052$ Overall findings showed that high-complex surgery is associated with greater risks of unsatisfactory results. Three studies used PROMs. One contracture study reported improvements in quality of life and disability by using validated questionnaires, and reported overall positive outcomes. ${ }^{63}$ Two cleft studies used self-developed questionnaires to assess PROMs, reporting positive results. ${ }^{6166}$ None of the studies reported on patient-reported outcomes on the quality of the care provided.

With regard to the sustainable characteristics of missions, 29 studies reported qualitative data $(71 \%)$ on sustainability, while none of the studies reported quantitative data. Fifteen out of twenty studies that reported on follow-up and complications also reported on sustainable characteristics such as long-term partnerships or training activities (table 4 ). Ten organisations (24\%) were engaged in longer-term partnerships, and thirteen missions (32\%) returned to the same regions or hospitals. Few data were available on the frequency of missions, although several studies reported conducting yearly missions. ${ }^{32} 354350$ Fifteen studies $(35 \%)$ described teaching objectives as a goal during their missions. Activities mentioned were lectures ${ }^{29} 3755$ training of local surgeons, ${ }^{16} 353854$ healthcare workers ${ }^{47560}$ or fellowships in donor countries. ${ }^{165455}$ 


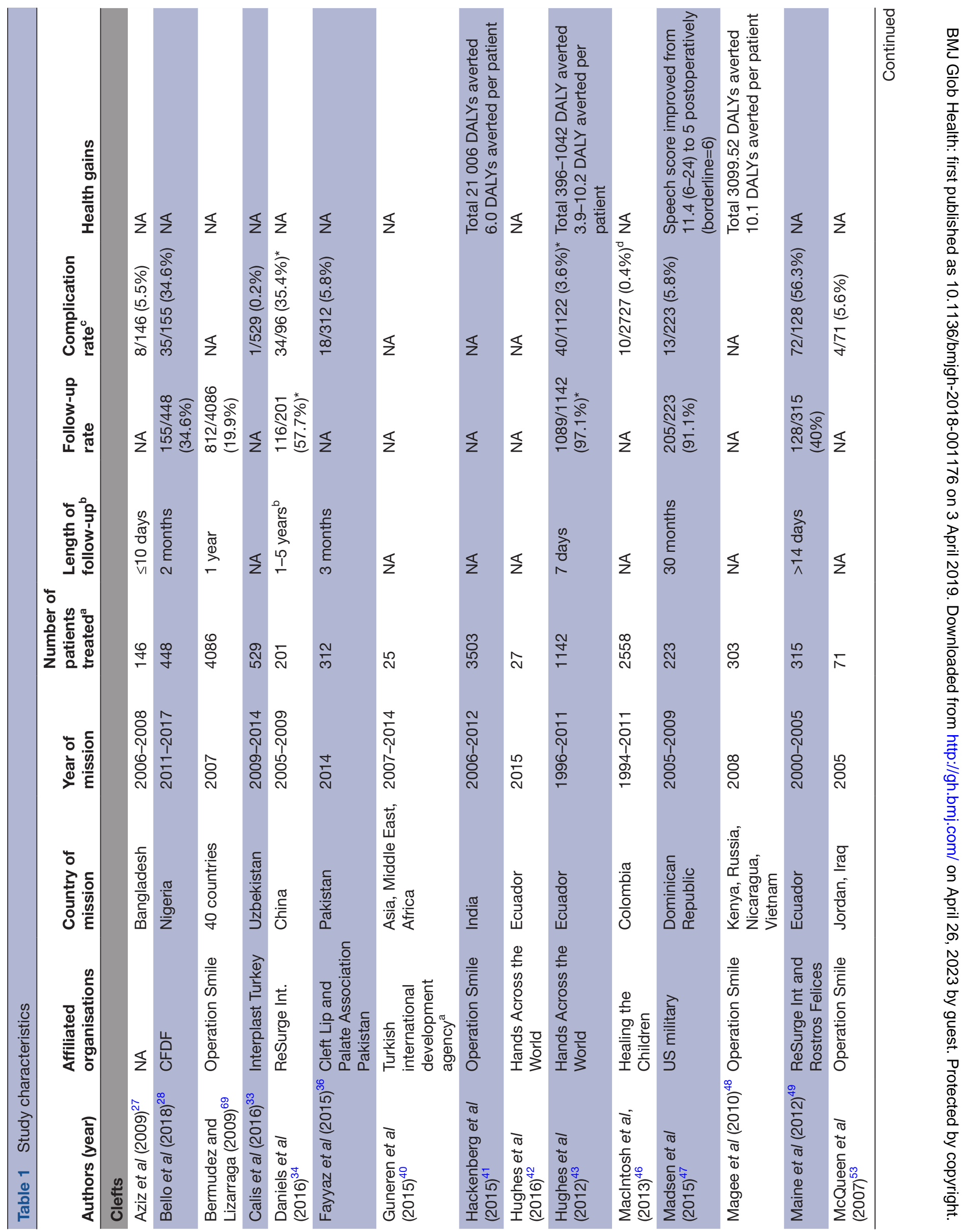




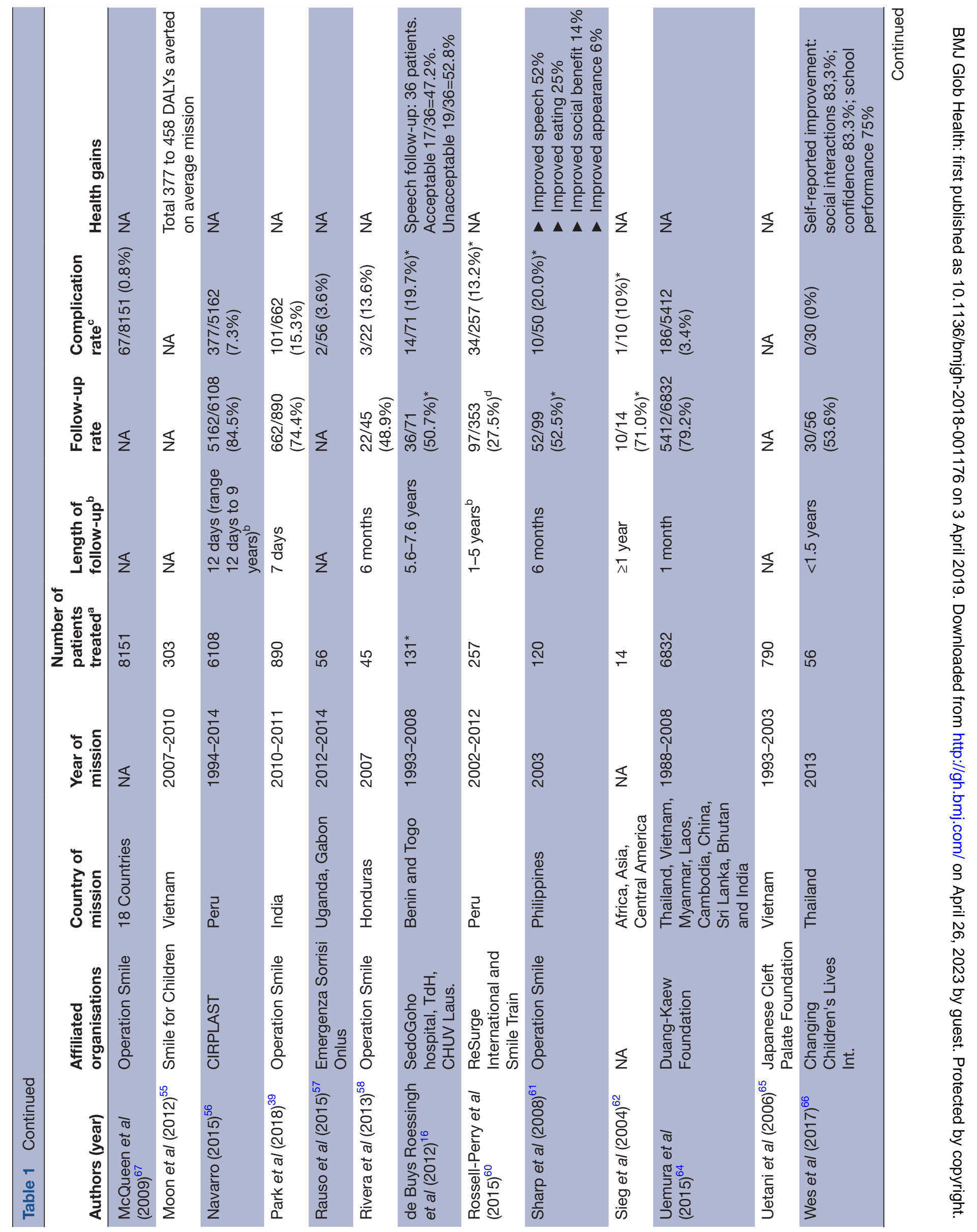




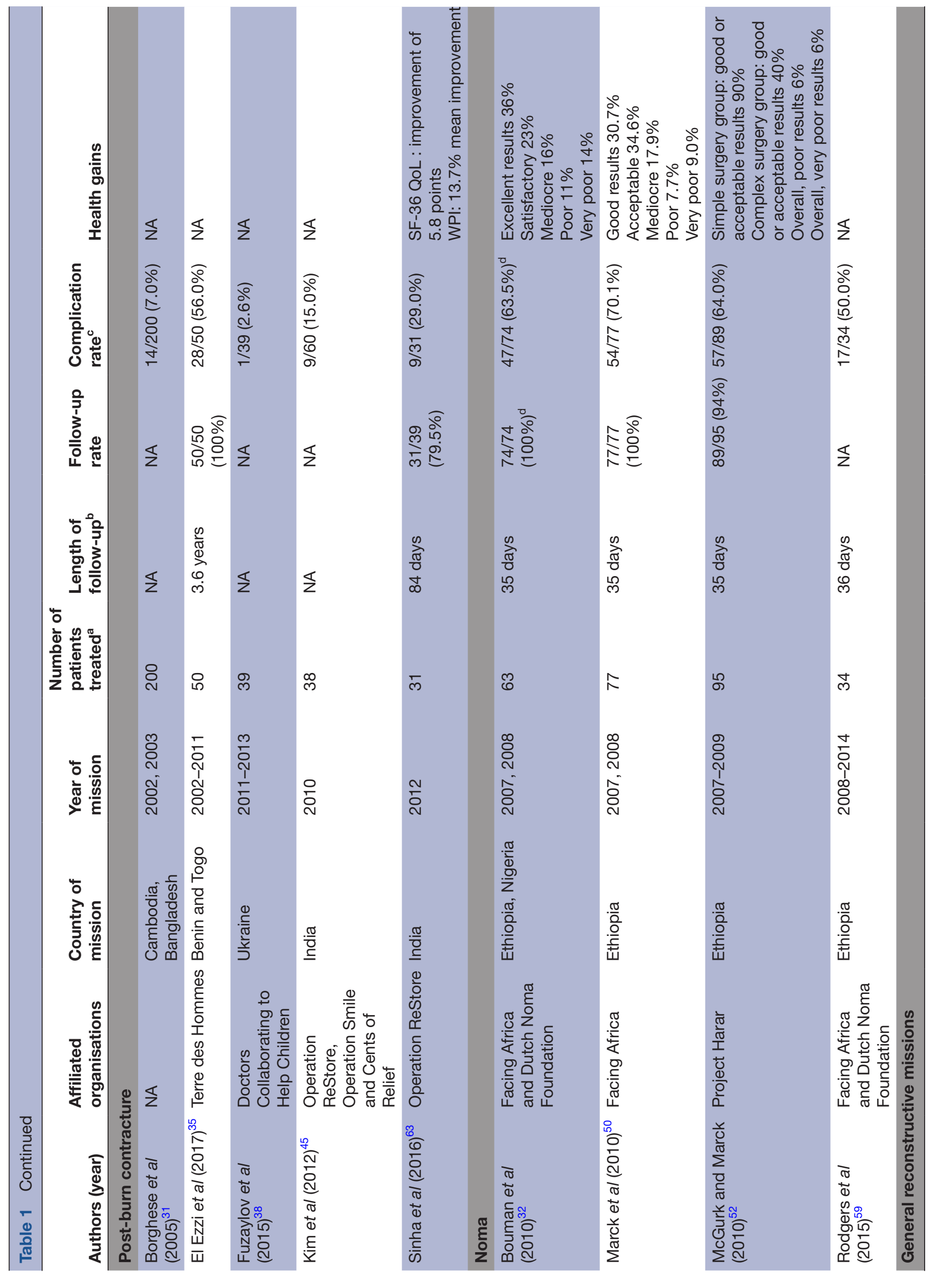




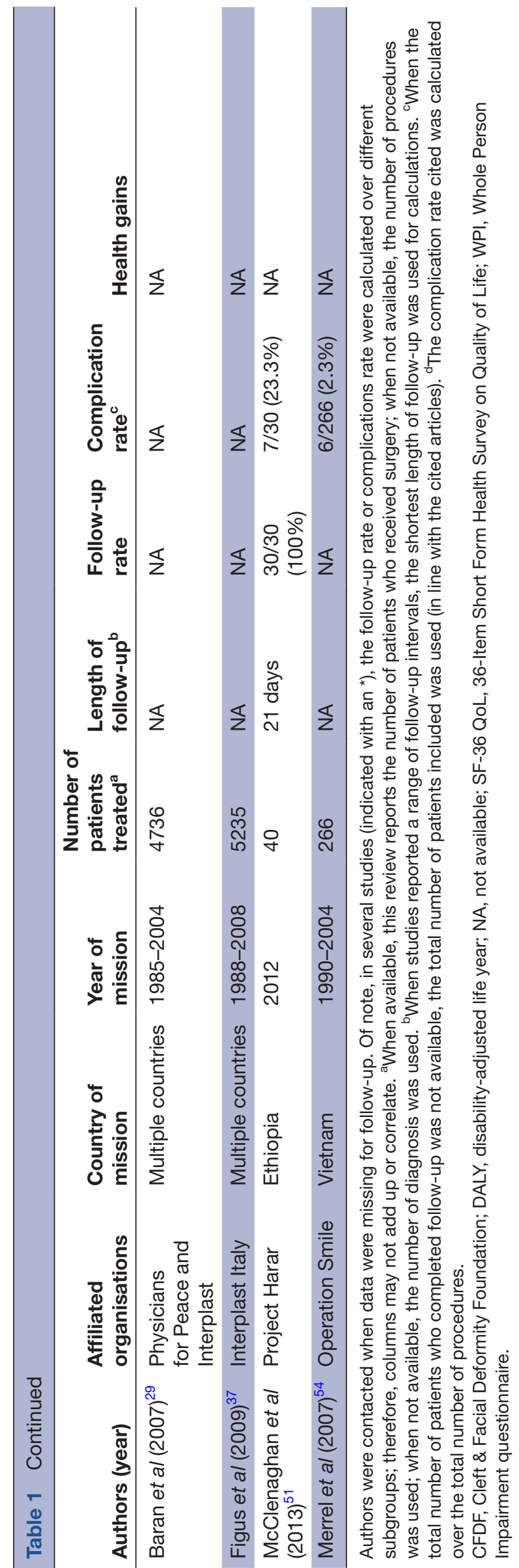

However, none of the studies published empirical data on the effects of training or elaborated on how the training of local healthcare personnel was organised.

Four cost-effectiveness studies were available for shortterm cleft missions. Three studies reviewed the effectiveness per DALY averted, reporting US\$33.94/DALY, ${ }^{48}$ US $\$ 56.0 / \mathrm{DALY}^{55}$ and US\$247.42/DALY. ${ }^{41}$ The variation is explained by the differences in study populations, sample sizes, effectiveness measurements and 'costing approaches' used.

\section{DISCUSSION}

Several systematic reviews about short-term medical missions are available. ${ }^{791012-15}$ This is the first systematic review that specifically assesses the quality of available data on short-term reconstructive surgical missions.

Although all the studies included in our review reported a positive impact of surgical missions, the level of evidence remains low. It seems that follow-up of treated patients is a challenge. Although a majority of studies provide data on complication rates, the varying quality of this outcome measure makes it difficult to draw any conclusions. The results showed that reported complication rates were considerably higher when the quality and length of follow-up increased. This suggests that without data on quality of follow-up, there is a high risk of reporting bias due to under-reporting of complications. This also means that without comprehensive information on follow-up, the safety of missions is likely to be overestimated.

Furthermore, studies used different control groups to benchmark their respective findings with regard to complication rates. Three of cleft care studies included compared complications between mission patients and patients who underwent similar procedures in a HIC. Results showed substantially higher complication rates in mission patients. ${ }^{34460}$ One study showed that fistula risk was 15.6 times that for a US cohort. ${ }^{34}$ Maine $e t a t^{49}$ state that complication rates were 20 times higher in the mission cohort compared with a US cohort, independently of whether the surgery was performed by Ecuadorian or American surgeons. It should be mentioned that comparisons of complication rates between HICs and LMICs cannot be made without taking into consideration that HICs have more resources at their disposal to limit complications. Therefore, we would suggest developing benchmark complication rates of LMICs, which can be used to assess the outcomes of short-term missions.

Some authors argue that longer-term specialty surgical hospitals may be provide more effective care than shortterm missions. ${ }^{9}{ }^{12} 39$ Specialty hospitals provide continuous care all year round in a LMIC. The cleft care centre of Operation Smile in India, ${ }^{39}$ or Smile Train's model are examples of this approach. ${ }^{69-78}$

Both organisations report lower complication rates than those reported in short-term missions. The centre of Operation Smile reports a short-term complication rate of $4.0 \%$ (cleft lip repair) and $15.8 \%$ (cleft palate repair), 


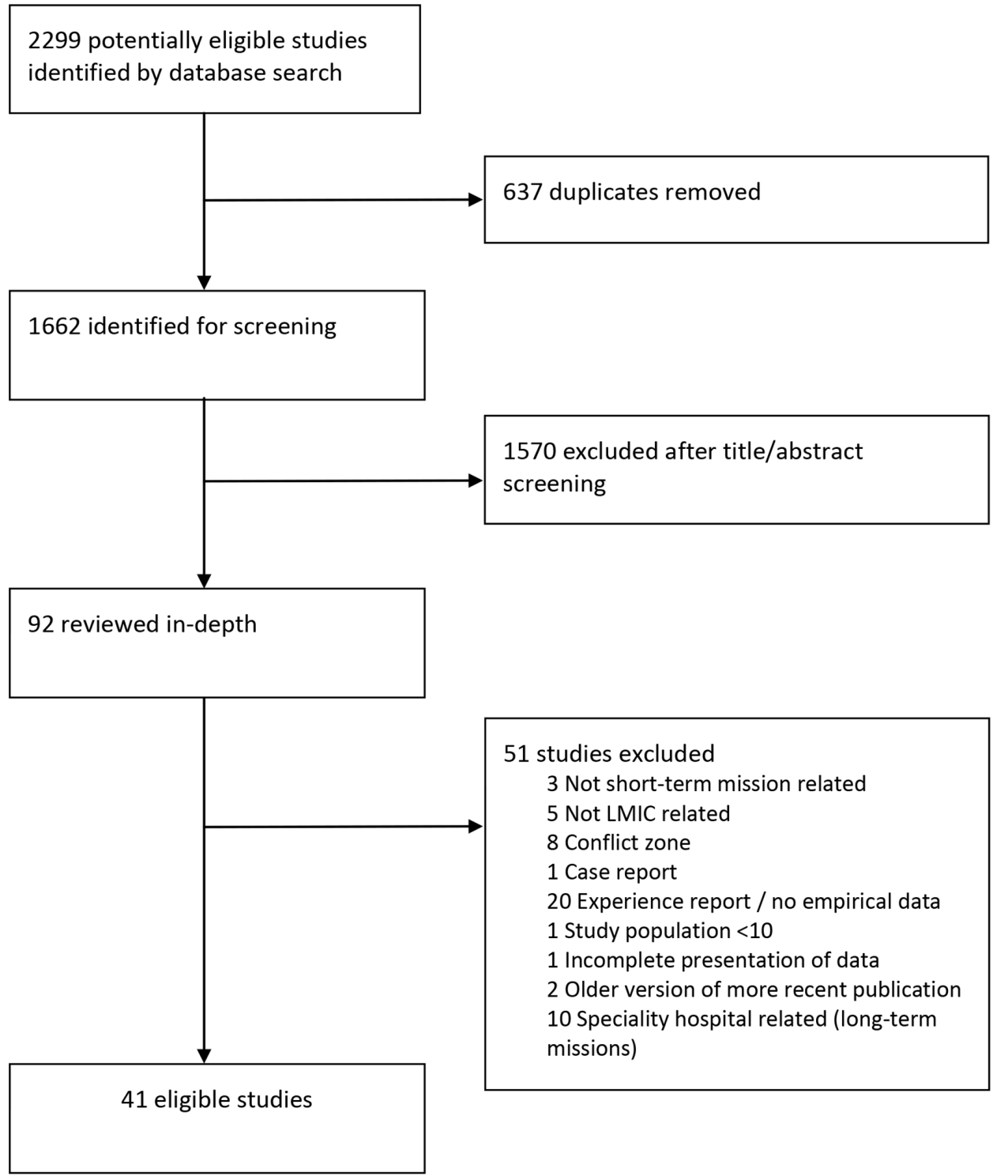

Figure 1 Flow diagram. LMIC, low-income and middle-income country.

which is lower than the rates of their counterpart shortterm missions. ${ }^{39}$ Smile Train studies report lower rates, between $0.88 \%$ and $3 \% .^{70717378}$ However, they note that there might be a risk of under-reporting or selection bias due to a dependence of Smile Train surgeons on payment-per-patient (risking fewer referrals when higher complication rates are reported) and a limited capacity of surgeons to treat complex cases. ${ }^{70717378}$ Furthermore, with only one Smile Train study reporting on follow-up lengths,${ }^{73}$ these complication rates should be interpreted with caution. To be able to compare the strengths and weaknesses of different approaches of providing surgical

\begin{tabular}{|c|c|c|c|}
\hline Type of missions & Number of studies included & Oxford CEBM Level of Evidence & Average GRADE score \\
\hline Cleft care mission studies & 28 studies & $\begin{array}{l}24 \text { Level IV studies (case series) } \\
4 \text { Level IIB (economic studies) }\end{array}$ & 2.6 (quality: low-moderate) \\
\hline Post-burn contractures mission studies & 5 studies & 5 Level IV studies (case series) & 3.4 (quality: moderate) \\
\hline Noma mission studies & 4 studies & 4 Level IV studies (case series) & 4.3 (quality: high) \\
\hline $\begin{array}{l}\text { General reconstructive surgery mission } \\
\text { studies }\end{array}$ & 4 studies & 4 Level IV studies (case series) & 1.3 (quality: very low-low) \\
\hline Overall quality and level of recommendation & 41 studies & $\begin{array}{l}\text { 37/41 Level IV studies } \\
4 / 41 \text { Level IIB studies } \\
\text { Level C recommendations }\end{array}$ & 2,7 (quality: low-moderate) \\
\hline
\end{tabular}

Information listed per condition. Quality assessment of included studies was performed using the GRADE system ${ }^{68}$ and Oxford CEBM Level of Evidence. 


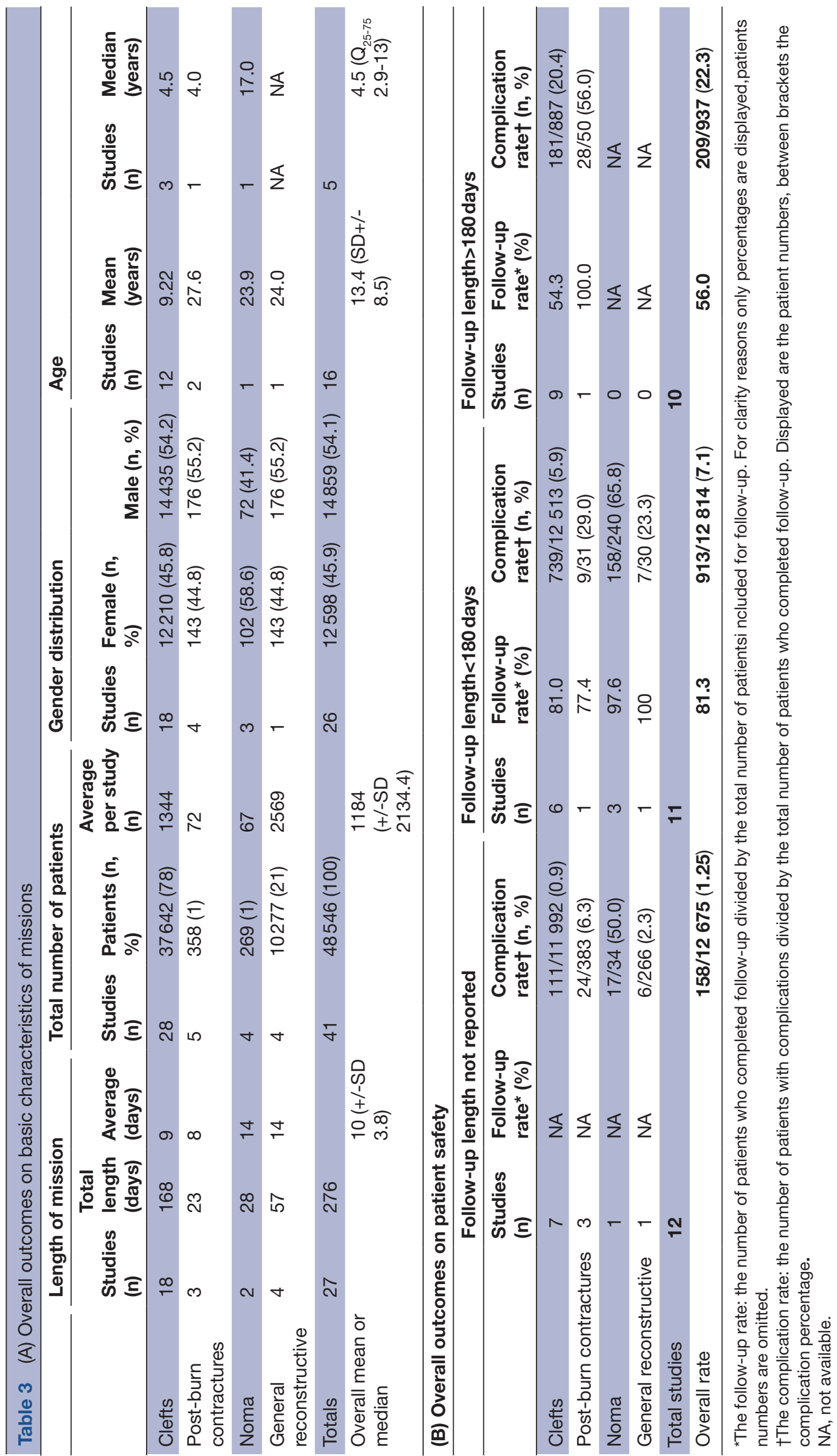

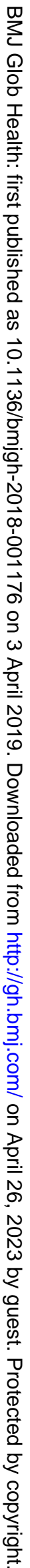




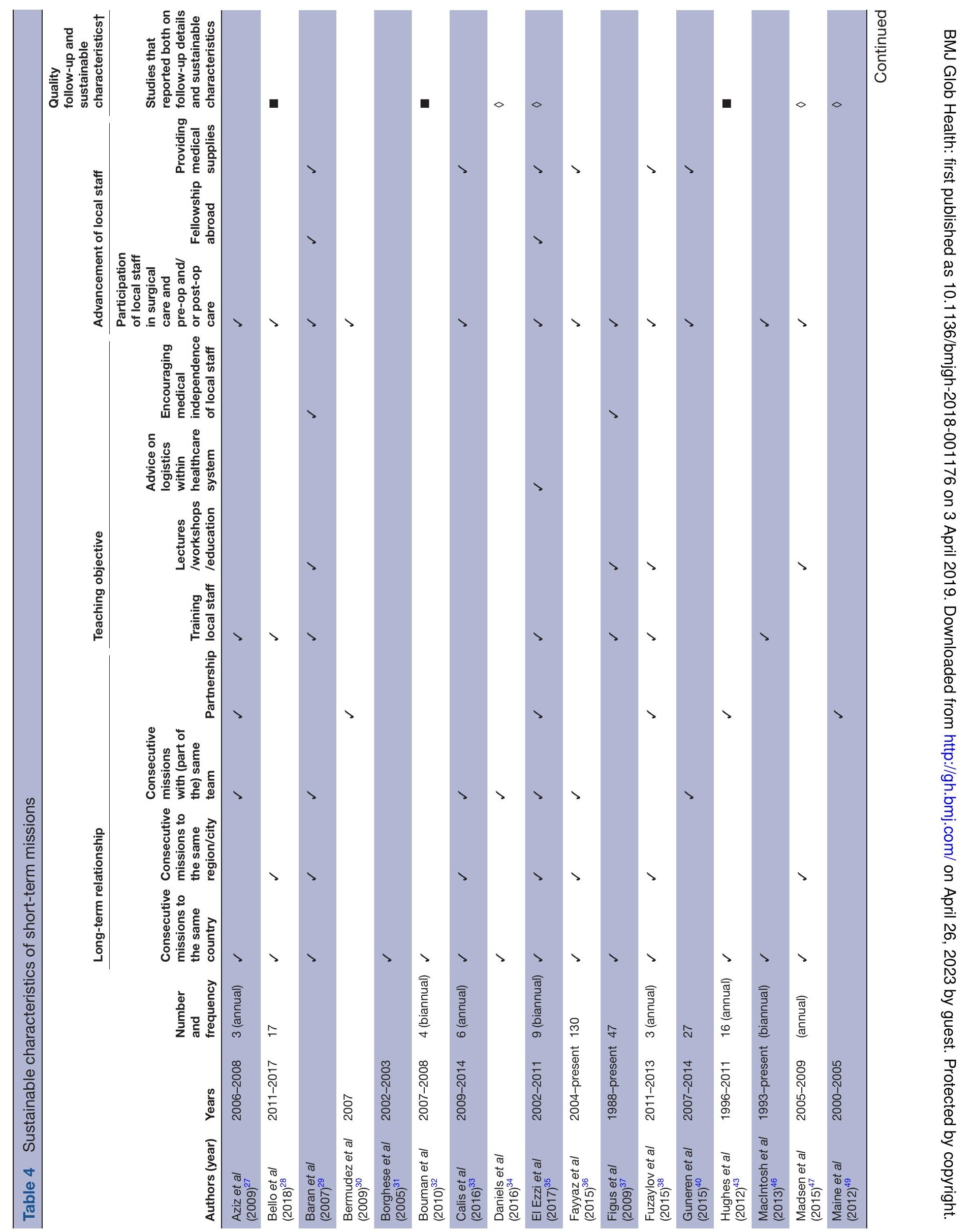




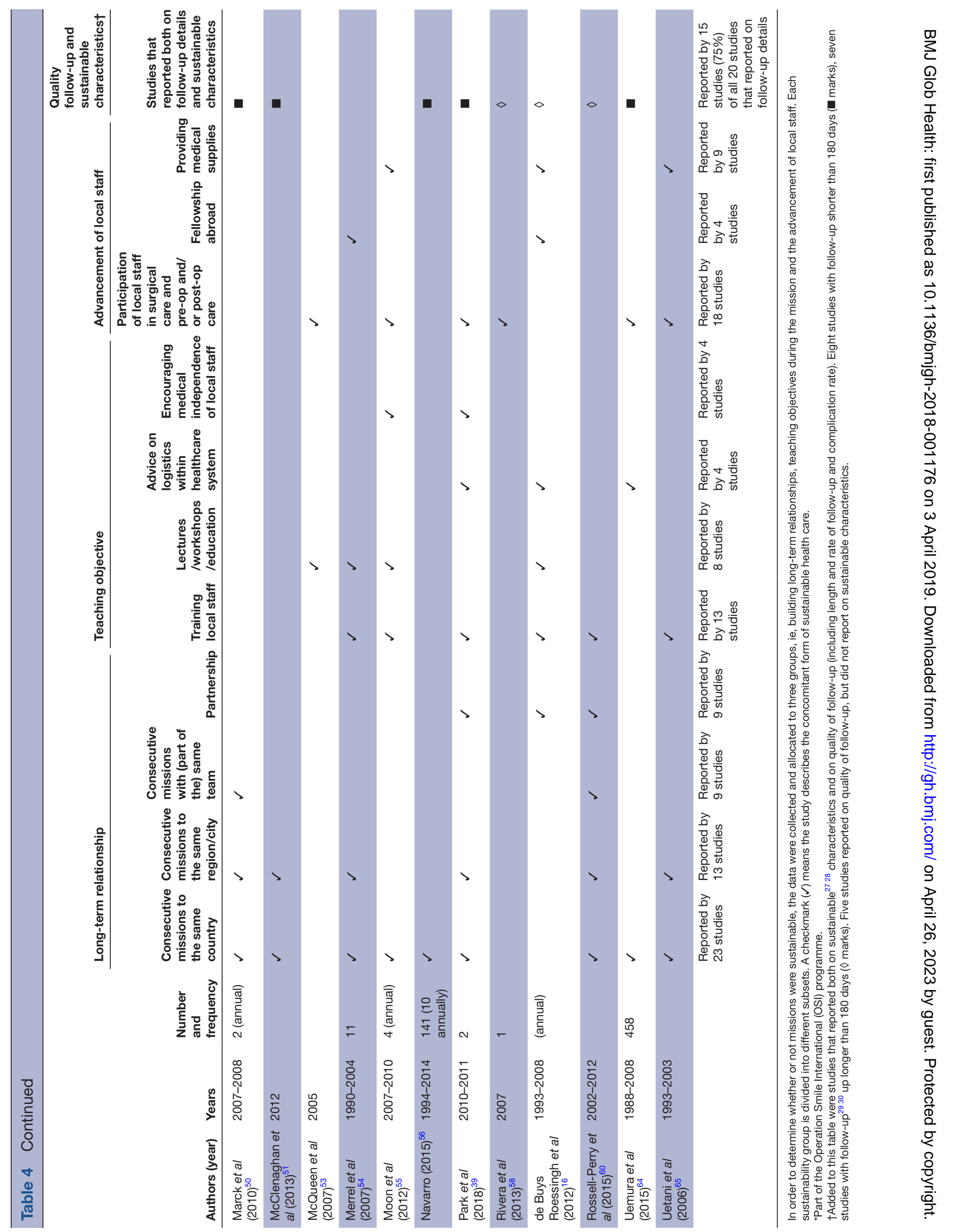


care in a LMIC, there is a need for more high-quality studies. ${ }^{12} 39$ Apart from registrations of complications, such studies should assess long-term outcome using validated outcome measures and PROMs. Specialty hospitals, which provide services all year round, could provide good conditions for longer-term outcome research.

Several studies in this review consistently report on follow-up, showing that substantial efforts are being made to improve the data output of missions. ${ }^{16343549-516163} \mathrm{Ten}$ studies reported significant follow-up lengths of more than 6 months and high numbers of patients returning for follow-up were shown. ${ }^{16} 343547495860-6266$ The majority of these missions were engaged in long-term partnerships. This included training of local healthcare personnel, which was likely to improve the feasibility of organising follow-up. Several strategies were implemented to ensure the quality of follow-up. Some missions deployed medical students to assess palate fistulas ${ }^{34}$ or sent a speech pathologist in-country to review outcomes. ${ }^{61}$ Others trained local surgeons on follow-up and revision surgery. ${ }^{54}$ The relatively high number of complications seen in noma missions could be partly explained by a stringent follow-up, done by an independent researcher who consistently reported on follow-up. All the studies mentioned above provide examples of how to ensure patient safety during and after missions. ${ }^{50} 79$

Although some studies reported on health gains, with several studies reporting positive functional outcomes, ${ }^{1647616366}$ the methods and evidence are heterogeneous and results are too limited to draw conclusions. The role of PROMs are effective in reconstructive surgery to assess the quality and outcomes of healthcare. ${ }^{80} 81$ Only few of the studies included reported successfully on outcomes using PROMs ${ }^{616366}$ and none assessed the quality of care experienced by patients. Patient experience of outcomes and quality is important. ${ }^{82}$ Future studies should include PROMS on surgical outcomes and quality of care. Only a few studies report on the sustainable characteristics of missions. Data on this topic are usually qualitative and highly variable. It is noteworthy that reporting on sustainability and higher quality of patient follow-up often go hand in hand. This suggests that more sustainable missions may be better able to follow their patients for a longer period. However, as empirical evidence on sustainability is still non-existent, there is an urgent need for further studies. ${ }^{12}$

\section{Limitations}

This systematic review has several limitations. Literature on short-term reconstructive missions is scarce and of limited quality, limiting the strength of this review. ${ }^{25}$ As the majority of studies are cleft studies, the conclusions and recommendations of this review may not be fully applicable to other types of reconstructive surgical missions.

The studies included represent just a small proportion of the many reconstructive surgical missions conducted worldwide. This may introduce a potential bias. It is likely that the small proportion likely does not fully represent the actual effect of all reconstructive surgical missions. In our view, this emphasises the need to incorporate standard monitoring and evaluations into missions.

Furthermore, this review addresses only short-term missions and does not attempt to make a direct comparison with long-term surgical platforms such as specialty hospitals. It is often argued that specialty hospitals are safer and have a more positive effect on local healthcare systems. $^{12} 76-788384$ Comparative studies of short-term missions and specialty hospitals can identify strengths and weaknesses of each approach. However, a definitive comparison between missions and specialty hospitals seems to be premature at present given the lack of comparative studies. ${ }^{1239}$

Concerns regarding the use of DALY metrics are applicable to the studies included in this review. It is argued that surgical conditions are underestimated in the global burden of disease studies. ${ }^{1}$ Attempts to estimate the surgical burden across all disease conditions have been challenging. ${ }^{85} 86$ In a recent study, it was argued that the current DALY approach is inadequate to quantify the burden of paediatric surgical conditions. ${ }^{87}$

\section{Recommendations}

There are opportunities for NGOs to develop short-term missions towards more sustainable partnerships. In the past, missions have been a 'vertical' approach to healthcare development. ${ }^{4}$ Such missions have limitations, for example in building local capacity of surgical services. The results of this study indicate that longer-term follow-up is frequently lacking, with complications being potentially missed. To address these shortcomings, the 'diagonal development' approach has been proposed. ${ }^{4}$ It combines the short-term vertical inputs of missions with longer-term horizontal benefits, with the ultimate aim of improving access to, and surgical capacity of, the local healthcare system. Such goals may be achieved through long-term development of surgical infrastructure, continued training of the local surgical workforce or building an academic culture. ${ }^{4}$

One example of such a diagonal approach is to aim for standardised tracking of longer-term outcomes of missions in strong collaboration with local partners. This might yield several advantages. Besides empowering local researchers and building an academic culture, outcomes can be reported back to patients and healthcare authorities. This will enhance the accountability of $\mathrm{NGOs}^{89}$ and allow for evaluations of the quality of care provided.

Another example of long-term investments in the local surgical capacity is strengthening of the training activities of surgical NGOs. Such activities should be integrated into existing national or regional training activities. The training should be adapted to local settings, needs-driven and should focus on bilateral knowledge exchange. ${ }^{4}$ 


\section{CONCLUSION}

This review shows that evidence for the effectiveness of short-term reconstructive surgical missions is both of limited substance and quality. Given the overall lack of evidence, there is an urgent need to incorporate outcomes research in future missions. This should include longer-term complication registration and measurements of health gains among individual patients. The effectiveness of training activities should also be evaluated. One approach to achieve this is to develop shortterm missions towards diagonal development missions, which aim to build surgical capacity of local healthcare systems through long-term investments.

Contributors The contributorship will be proceeded with the plastic surgery department at VU University Medical Center Amsterdam.

Funding The authors have not declared a specific grant for this research from any funding agency in the public, commercial or not-for-profit sectors.

Competing interests None declared.

Patient consent for publication Not required.

Provenance and peer review Not commissioned; externally peer reviewed.

Open access This is an open access article distributed in accordance with the Creative Commons Attribution Non Commercial (CC BY-NC 4.0) license, which permits others to distribute, remix, adapt, build upon this work non-commercially, and license their derivative works on different terms, provided the original work is properly cited, appropriate credit is given, any changes made indicated, and the use is non-commercial. See: http://creativecommons.org/licenses/by-nc/4.0/.

\section{REFERENCES}

1. GBD 2016 DALYs and HALE Collaborators. Global, regional, and national disability-adjusted life-years (DALYs) for 333 diseases and injuries and healthy life expectancy (HALE) for 195 countries and territories, 1990-2016: a systematic analysis for the Global Burden of Disease Study 2016. Lancet 2017;390:1260-344.

2. Srour ML, Marck K, Baratti-Mayer D. Noma: overview of a neglected disease and human rights violation. Am J Trop Med Hyg 2017:96:268-74.

3. Meara JG, Leather AJ, Hagander L, et al. Global surgery 2030 : evidence and solutions for achieving health, welfare, and economic development. Lancet 2015;386:569-624.

4. Patel PB, Hoyler M, Maine R, et al. An opportunity for diagonal development in global surgery: cleft lip and palate care in resourcelimited settings. Plast Surg Int 2012;2012:1-10.

5. Patel PS, Chung KY, Kasrai L. Innovate global plastic and reconstructive surgery: cleft lip and palate charity database. $J$ Craniofac Surg 2018;29:937-42.

6. Ng-Kamstra JS, Riesel JN, Arya S, et al. Surgical non-governmental organizations: global surgery's unknown nonprofit sector. World $\mathrm{J}$ Surg 2016;40:1823-41.

7. Martiniuk AL, Manouchehrian M, Negin JA, et al. Brain gains: a literature review of medical missions to low and middle-income countries. BMC Health Serv Res 2012;12.

8. Caldron $\mathrm{PH}$, Impens $\mathrm{A}$, Pavlova $\mathrm{M}$, et al. A systematic review of social, economic and diplomatic aspects of short-term medical missions. BMC Health Serv Res 2015;15.

9. Kynes JM, Zeigler L, McQueen K. Surgical outreach for children by international humanitarian organizations: a review. Children 2017;4:e53.

10. Sykes KJ. Short-term medical service trips: a systematic review of the evidence. Am J Public Health 2014;104:e38-48.

11. Maki J, Qualls M, White B, et al. Health impact assessment and short-term medical missions: a methods study to evaluate quality of care. BMC Health Serv Res 2008;8.

12. Shrime MG, Sleemi A, Ravilla TD. Charitable platforms in global surgery: a systematic review of their effectiveness, costeffectiveness, sustainability, and role training. World J Surg 2015;39:10-20.

13. Chung KY. Plastic and reconstructive surgery in global health: let's reconstruct global surgery. Plast Reconstr Surg Glob Open 2017;5:e1273.
14. Roche SD, Ketheeswaran P, Wirtz VJ. International short-term medical missions: a systematic review of recommended practices. Int J Public Health 2017;62:31-42.

15. Nolte MT, Maroukis BL, Chung KC, et al. A systematic review of economic analysis of surgical mission TRIPS using the World Health Organization criteria. World J Surg 2016;40:1874-84.

16. de Buys Roessingh AS, Dolci M, Zbinden-Trichet $C$, et al. Success and failure for children born with facial clefts in Africa: a 15-year follow-up. World J Surg 2012;36:1963-9.

17. Wall A. The context of ethical problems in medical volunteer work. HEC Forum 2011;23:79-90

18. Ahmed F, Grade M, Malm C, et al. Surgical volunteerism or voluntourism - are we doing more harm than good? Int J Surg 2017;42:69-71.

19. Grimes CE, Henry JA, Maraka J, et al. Cost-effectiveness of surgery in low- and middle-income countries: a systematic review. World J Surg 2014;38:252-63.

20. Liberati A, Altman DG, Tetzlaff J, et al. The PRISMA statement for reporting systematic reviews and meta-analyses of studies that evaluate healthcare interventions: explanation and elaboration. $B M J$ 2009;339:b2700.

21. Chao TE, Sharma K, Mandigo M, et al. Cost-effectiveness of surgery and its policy implications for global health: a systematic review and analysis. Lancet Glob Health 2014;2:e334-45.

22. Byass P. The imperfect world of global health estimates. PLoS Med 2010;7:e1001006.

23. Byass P, de Courten M, Graham WJ, et al. Reflections on the globa burden of disease 2010 estimates. PLoS Med 2013;10:e1001477.

24. Alkire B. Benefit-cost analysis for selected surgical interventions in low and middle income countries. In: Debas HT, Donkor P, eds. Disease control priorities. 3 edn. World Bank, 2015.

25. CEBM. Oxford Centre for Evidence-based Medicine-Levels of Evidence (March 2009), 2018. Available: http://www.cebm.net/ oxford-centre-evidence-based-medicine-levels-evidence-march2009 [Accessed 5 May 2018]

26. Atkins D, Best D, Briss PA, et al. Grading quality of evidence and strength of recommendations. BMJ 2004;328:1490.

27. Aziz SR, Rhee ST, Redai I. Cleft surgery in rural Bangladesh: reflections and experiences. J Oral Maxillofac Surg 2009;67:1581-8.

28. Bello SA, Balogun SA, et al. Outreach model: 6 year experience of an Indigenous Nigerian mission in the surgical correction of facial clefts. PAMJ2018;29.

29. Baran CN, Tiftikcioglu YO, Peace Pfor. Physicians for peace and Interplast Turkiye: combined humanitarian surgical activities and conferences. Plast Reconstr Surg 2007;119:1077-90.

30. Bermudez L, Carter V, Magee W, et al. Surgical outcomes auditing systems in humanitarian organizations. World J Surg 2010;34:403-10.

31. Borghese L, Latorre S, Montagnese A, et al. Retrospective analysis of 200 severe post-burn cases in Cambodia and Bangladesh. Ann Burns Fire Disasters 2005;18:5-10.

32. Bouman MA, Marck KW, Griep JEM, et al. Early outcome of noma surgery. J Plast Reconstr Aesthet Surg 2010;63:2052-6.

33. Calis M, Aral AM, Sencan A, et al. Humanitarian activities of Interplast Turkiye: 6 years of experience in Uzbekistan for surgical treatment of cleft patients and related secondary deformities. Ann Plast Surg 2016;77:494-8.

34. Daniels KM, Yang Yu E, Maine RG, et al. Palatal fistula risk after primary palatoplasty: a retrospective comparison of a humanitarian organization and tertiary hospitals. Cleft Palate Craniofac $J$ 2018;16007.

35. El Ezzi O, Dolci M, Dufour $C$, et al. Surgery on burns sequelae in developing countries. Ann Burn Fire Disasters 2017;30:47-51.

36. Fayyaz GQ, Gill NA, Ishaq I, et al. A model humanitarian cleft mission: 312 cleft surgeries in 7 days. Plast Reconstr Surg Glob Open 2015;3:e313.

37. Figus A, Fioramonti P, Morselli P, et al. Interplast Italy: a 20-year plastic and reconstructive surgery humanitarian experience in developing countries. Plast Reconstr Surg 2009;124:1340-8.

38. Fuzaylov G, Anderson R, Knittel J, et al. Global health: burn outreach program. J Burn Care Res 2015;36:306-9.

39. Park E, Deshpande G, Schonmeyr B, et al. Improved early cleft lip and palate complications at a surgery specialty center in the developing world. Cleft Palate Craniofac J 2018;1055665618762881.

40. Guneren E, Canter HI, Yildiz K, et al. One-stage cleft lip and palate repair in an older population. J Craniofac Surg 2015;26:e426-30.

41. Hackenberg B, Ramos MS, Campbell A, et al. Measuring and comparing the cost-effectiveness of surgical care delivery in lowresource settings. J Craniofac Surg 2015;26:1121-5.

42. Hughes C, Campbell J, Mukhopadhyay S, et al. Remote digital preoperative assessments for cleft lip and palate may improve 
clinical and economic impact in global plastic surgery. Cleft Palate Craniofac J 2017;54:535-9.

43. Hughes CD, Babigian A, McCormack S, et al. The clinical and economic impact of a sustained program in global plastic surgery: valuing cleft care in resource-poor settings. Plast Reconstr Surg 2012;130:87e-94.

44. Johnson BD. Short term surgical mission evaluation: a medical record analysis. Ann Arbor [PhD]. San Francisco, University of California, 2011.

45. Kim FS, Tran HH, Sinha I, et al. Experience with corrective surgery for postburn contractures in Mumbai, India. J Burn Care Res 2012;33:e120-6.

46. Maclntosh RB, Herman LT, Shivapuja PK, et al. Volunteer cleft surgery in Colombia: an 18-year perspective. J Oral Maxillofac Surg 2013;71:1742-51

47. Madsen C, Lough D, Lim A, et al. Cleft and craniofacial care during military pediatric plastic surgery humanitarian missions. J Craniofac Surg 2015;26:1097-101.

48. Magee WP, Vander Burg R, Hatcher KW. Cleft lip and palate as a cost-effective health care treatment in the developing world. World $\mathrm{J}$ Surg 2010;34:420-7.

49. Maine RG, Hoffman WY, Palacios-Martinez JH, et al. Comparison of fistula rates after palatoplasty for international and local surgeons on surgical missions in Ecuador with rates at a craniofacial center in the United States. Plast Reconstr Surg 2012;129:319e-26.

50. Marck R, Huijing M, Vest D, et al. Early outcome of facial reconstructive surgery abroad: a comparative study. Eur J Plast Surg 2010;33:193-7.

51. McClenaghan F, Fell M, Martin D, et al. Surgical mission planning in the developing world. Int J Oral Maxillofac Surg 2013;42:1587-91.

52. McGurk M, Marck R. Treatment of noma: medical missions in Ethiopia. Br Dent J 2010;208:179-82.

53. McQueen KAK, Burkle FM, Al-Gobory ET, et al. Maintaining baseline, corrective surgical care during asymmetrical warfare: a case study of a humanitarian mission in the safe zone of a neighboring country. Prehosp Disaster Med 2007;22:3-7. discussion 8.

54. Merrell JC, Tien NV, Son NT, et al. Introduction of microsurgery in Vietnam by a charitable organization: a 15-year experience. Plast Reconstr Surg 2007;119:1267-73. discussion 74-5.

55. Moon W, Perry H, Baek R-M. Is international volunteer surgery for cleft lip and cleft palate a cost-effective and justifiable intervention? A case study from East Asia. World J Surg 2012;36:2819-30.

56. Navarro CE. CIRPLAST: cleft lip and palate missions in Peru. $J$ Craniofac Surg 2015;26:1109-11.

57. Rauso R, Onesti M, Scuderi N. Unilateral cleft lip repair during charity missions: a consideration about simultaneously lip and nose repair. Minerva Stomatol 2015;64:203-12.

58. Rivera ME, Hexem KR, Womer JW, et al. Parents' satisfaction with repair of paediatric cleft lip/cleft palate in Honduras. Paediatr Int Child Health 2013;33:170-5.

59. Rodgers W, Lloyd T, Mizen K, et al. Microvascular reconstruction of facial defects in settings where resources are limited. $\mathrm{Br} J$ Oral Maxillofac Surg 2016;54:51-6.

60. Rossell-Perry P, Segura E, Salas-Bustinza L, et al. Comparison of two models of surgical care for patients with cleft lip and palate in resource-challenged settings. World J Surg 2015;39:47-53.

61. Sharp HM, Canady JW, Ligot FAC, et al. Caregiver and patient reported outcomes after repair of cleft lip and/or palate in the Philippines. Cleft Palate Craniofac J 2008;45:163-71.

62. Sieg P, Hakim SG, Jacobsen $\mathrm{H}-\mathrm{C}$, et al. Rare facial clefts: treatment during charity missions in developing countries. Plast Reconstr Surg 2004; 114:640-7.

63. Sinha I, Zhu D, Ojomo K, et al. Functional and subjective assessment of burn contracture release in a mission setting. Burns 2016;42:466-70.

64. Uemura T, Preeyanont P, Udnoon S. Humanitarian cleft lip/palate surgeries in Buddhist Thailand and neighboring countries. $J$ Craniofac Surg 2015;26:1112-5.
65. Uetani M, Jimba M, Niimi T, et al. Effects of a long-term volunteer surgical program in a developing country: the case in Vietnam from 1993 to 2003. Cleft Palate Craniofac J 2006;43:616-9.

66. Wes AM, Paul N, Gerety PA, et al. A sustainable model for patient follow-up following an international cleft mission. Cleft Palate Craniofac J 2018;55:977-82.

67. McQueen KAK, Magee W, Crabtree T, et al. Application of outcome measures in international humanitarian aid: comparing indices through retrospective analysis of corrective surgical care cases. Prehosp Disaster Med 2009;24:39-46.

68. Atkins D, Best D, Briss PA, et al. Grading quality of evidence and strength of recommendations.. In: BMJ. , 2004: 328, 1490.

69. Bermudez LE, Lizarraga AK. Operation SMILE: how to measure its success. Ann Plast Surg 2011;67:205-8.

70. Brydon CA, Conway J, Kling R, et al. Cleft lip and/or palate: one organization's experience with more than a quarter million surgeries during the past decade. J Craniofac Surg 2014;25:1601-9.

71. Conway JC, Taub PJ, Kling R, et al. Ten-year experience of more than 35,000 orofacial clefts in Africa. BMC Pediatr 2015;15.

72. Cubitt JJ, Hodges AM, Van Lierde KM, et al. Global variation in cleft palate repairs: an analysis of 352,191 primary cleft repairs in low- to higher-middle-income countries. Cleft Palate Craniofac $J$ 2014;51:553-6.

73. Fell MJ, Hoyle T, Abebe ME, et al. The impact of a single surgical intervention for patients with a cleft lip living in rural Ethiopia. $J$ Plast Reconstr Aesthet Surg 2014;67:1194-200.

74. Gupta K, Gupta P, Bansal P, et al. Anesthetic management for SMILE train a blessing for population of low socioeconomic status: a prospective study. Anesth Essays Res 2010;4:81-4.

75. Abenavoli FM, Altacera M, et al. Humanitarian cleft mission to central Africa-experience and suggestions. J Postgrad Med 2011;25:373--5.

76. Corlew DS, Alkire BC, Poenaru D, et al. Economic valuation of the impact of a large surgical charity using the value of lost welfare approach. BMJ Global Health 2016;1:e000059.

77. Poenaru D. Getting the job done: analysis of the impact and effectiveness of the SmileTrain program in alleviating the global burden of cleft disease. World J Surg 2013;37:1562-70.

78. Poenaru D, Lin D, Corlew S. Economic valuation of the global burden of cleft disease averted by a large cleft charity. World J Surg 2016;40:1053-9.

79. Huijing MA, Marck KW, Combes J, et al. Facial reconstruction in the developing world: a complicated matter. Br J Oral Maxillofac Surg 2011;49:292-6.

80. Chow A, Mayer EK, Darzi AW, et al. Patient-reported outcome measures: the importance of patient satisfaction in surgery. Surgery 2009;146:435-43.

81. Pusic AL, Lemaine V, Klassen AF, et al. Patient-reported outcome measures in plastic surgery: use and interpretation in evidencebased medicine. Plast Reconstr Surg 2011:127:1361-7.

82. Kruk ME, Pate M, Mullan Z. Introducing the Lancet Global Health Commission on high-quality health systems in the SDG era. Lancet Glob Health 2017:5:e480-1.

83. Campbell A, Restrepo C, Mackay D, et al. Scalable, sustainable cost-effective surgical care: a model for safety and quality in the developing world. Part III: impact and sustainability. J Craniofac Surg 2014;25:1685-9.

84. Persing S, Patel A, Clune JE, et al. The repair of international clefts in the current surgical landscape. J Craniofac Surg 2015;26:1126-8.

85. Bickler S, Ozgediz D, Gosselin R, et al. Key concepts for estimating the burden of surgical conditions and the unmet need for surgical care. World J Surg 2010;34:374-80.

86. Gosselin R, Ozgediz D, Poenaru D. A square peg in a round hole? Challenges with DALY-based "burden of disease" calculations in surgery and a call for alternative metrics. World $J$ Surg 2013;37:2507-11.

87. Smith ER, Concepcion T, Lim S, et al. Disability weights for pediatric surgical procedures: a systematic review and analysis. World J Surg 2018:42:3021-34. 